\title{
A Longitudinal Analysis of Doctoral Graduate Supply in the
}

\section{Educational Measurement Field}

\author{
Jennifer Randall ${ }^{\mathrm{a}}$ and Joseph A. Rios ${ }^{\mathrm{b}}$, Hyun Joo Jung ${ }^{\mathrm{a}}$ \\ aniversity of Massachusetts Amherst \\ ${ }^{b}$ University of Minnesota
}

Authors' Note

The authors would like to thank Darius Singpurwalla and Kelly Kang, project officers for the Survey of Earned Doctorates, for their assistance in obtaining data related to nationality, ethnicity, and subfield for individuals majoring in educational assessment. An additional thank you is owed to Samuel Ihlenfeldt at the University of Minnesota for providing helpful feedback. A version of this work was presented at the 2019 annual conference of the National Council on Measurement in Education in Toronto, Canada.

Author Contribution Statement: The first and second authors conceived of the presented idea. The third author performed data cleaning and analyses. The first two authors jointly wrote the manuscript and managed critical revisions throughout the review process. Final approval of the version to be published was made by all authors.

Correspondence concerning this article should be sent to Jennifer Randall, University of Massachusetts Amherst, 813 N. Pleasant St., Amherst, MA 01002

Email: jrandall@umass.edu 


\begin{abstract}
For nearly three decades, researchers have been concerned that the educational measurement field is not producing enough graduate-level specialists to meet the growing demand driven by the increased use of educational assessments in the U.S. This study examined the supply-side aspect of the proposed labor shortage by relying on data from the National Science Foundation's Survey of Earned Doctorates collected between 1997 and 2016. Over the 20 years examined, measurement programs produced 3,124 doctoral graduates, and across this time span, the annual production of graduates nearly doubled. This supply expansion can largely be attributed to the increase in the number of international graduates, which outpaced the annual growth rate of domestic $\mathrm{PhD}$ recipients by $156 \%$. Moreover, $85 \%$ of graduates were found to either selfidentify as White or Asian. Less than 10 Hispanic and no more than 20 Black graduates were produced in any of the years examined. Of the $76 \%$ of graduates that reported having a job offer or accepted a position upon graduation, most entered the academy despite the overall average starting salary $(\$ 59,484)$ being considerably lower than the starting salary for their counterparts entering industry $(\$ 84,918)$, government $(\$ 69,970)$, or other educational institutions $(\$ 81,428)$.
\end{abstract}

Keywords: diversity, doctoral education, graduate supply, educational measurement, psychometrics, gender disparity, race disparity, STEM doctoral education 


\section{A Longitudinal Analysis of Doctoral Graduate Supply in the Educational Measurement Field}

The effective development and use of educational assessments within the United States is dependent on having a highly trained workforce of educational measurement specialists. However, over the last 20 years, the measurement community has warned that there is a significant shortage of well-trained graduate students to fill the measurement positions created by the increased demand for educational testing in accountability, admissions, credentialing, and formative assessment contexts (Brennan, 2004; Finney \& Pastor, 2012; Patellis et al., 1997; Sireci, 2000). As noted by Brennan (2004), this shortage results in “...persons filling the positions [that] do not always have the qualifications and experience required to do the job well...” (p. 22). As a consequence, numerous aspects of educational measurement may be impeded, such as developing quality assessments to measure increasingly complex constructs, protecting the public from potential misuse of test scores, and identifying novel solutions to problems confronting educational measurement practice (e.g., test security, providing effective feedback). Measurement scholars have suggested that this shortage in measurement specialists can be attributed to, at least in part, the lack of ethnic minority recruitment in the field (Brennan \& Plake, 1990; Sireci, 2000). Still increasing calls for a more diverse assessment community (Sireci, 2000; Rios et al., 2019) have gone largely unanswered. To be sure, developing and maintaining a well-trained and diverse pipeline of measurement specialists is critical to the field. To assist in better understanding this issue, the objective of this paper is to examine the supplyside aspect of the labor shortage within the United States by relying on longitudinal historical data collected by the U.S. federal government. 


\section{Prior Literature Examining the Supply of Educational Measurement Specialists}

Previous research that has examined the supply of educational measurement specialists has either studied a crop of graduate students or members of measurement-related professional organizations. The initial attempt to investigate this issue was motivated by the National Council on Measurement in Education's (NCME) Committee on Recruiting Educational Measurement Professionals in the 1990s. As an example, Brennan and Plake (1990) surveyed NCME members affiliated with higher education institutions to ascertain the number of current students in their programs as well as the expected future enrollment rates. Across 108 institutions, they found that on average the number of masters and doctoral programs had approximately five and nine students, respectively. Furthermore, respondents reported that enrollment rates were likely to remain stable for both masters and doctoral programs. In regard to demographic information, the authors found that approximately $30 \%$ of all graduate students in educational measurement in 1990 were foreign nationals.

In a follow-up study, Patellis et al. (1997) reached out to every institution ( $\mathrm{n}=152)$ with at least one NCME member. Based on responses from 60 institutions (response rate $=39 \%$ ), the authors discovered that, when compared to the findings in 1990, the average number of doctoral students increased (11.8), while individuals in master's programs declined (4). Though there was a decrease in the average number of master's students, faculty members indicated that they expected future graduate student enrollment to increase in the field, which would be addressed by hiring more professors of educational measurement. The percentage of foreign national students in masters and doctoral programs in 1996 was $21 \%$ and $32 \%$, respectively. Nearly $60 \%$ of these foreign nationals were Asian/Pacific Islander. In terms of ethnicity, differences were noted between masters and doctoral programs. For the former, the majority of students were 
White (67\%) followed by Hispanic (15\%), Asian/Pacific Islander (13\%), and Black (5\%)

students. A similar percentage of White students were noted for doctoral programs, but the percentage of Asian/Pacific Islanders was much higher (24\%), while Blacks (5\%) and Hispanics (2\%) made up a small minority.

In a more recent study conducted by Packman, et al. (2010), members of NCME, the National Association of Test Directors, and the Evaluation, Measurement, and Statistics Division of the American Psychological Association were surveyed in 2007 to obtain information about their demographics, educational background, and employment history. Overall, the authors found that a total of 1,722 unique individuals belonged to these measurement organizations, however, only 538 members responded to the survey. Of these individuals, the majority of respondents were male (55.5\%) and over the age of 50 (53.5\%). In terms of ethnicity, Caucasians comprised $82 \%$ of the sample, followed by Asian Americans at $8.8 \%$. Approximately, $66 \%$ of the members participating in the survey indicated that their highest degree was a $\mathrm{PhD}$ earned primarily in the fields of educational research, evaluation, or measurement (49.1\%), quantitative methods/psychometrics (29.3\%), educational psychology (19.8\%), and statistics (7.7\%). The surveyed measurement specialists were found to work predominately in academic (37.2\%) and research/testing (37.2\%) settings, followed by educational or governmental agencies $(9.5 \%)$. However, it appeared that many respondents were new to the field as less than $40 \%$ working at research/testing organizations had more than five years of experiences, while across all positions the median tenure was only two to five years. Furthermore, $11 \%$ of respondents indicated that they were prepared to retire or reduce their workload to a part-time basis within three years of the survey. 


\section{Rationale for Current Study}

Although providing useful information, these studies are limited in a number of ways. First, data examining the supply of educational measurement graduates were collected approximately 10 to 30 years ago; thus, making it difficult to generalize to supply presently. Second, due to the use of surveys, a high degree of nonresponse rates was observed across studies (ranging from 30-60\%), which may have made it difficult to provide a clear summary of the graduate student or professional samples surveyed. Third, for each study, data collection occurred over a few months, consequently ignoring variability over time and treating supply as static. Lastly, and most importantly, previous literature on this topic attempted to study supply indirectly by extrapolating information about graduate cohorts to make inferences about the supply of measurement specialists or by examining overall membership in education-related professional organizations as a representation of the overall supply of measurement specialists. To be sure, each approach makes several assumptions. For instance, when surveying faculty members, it is assumed that they know the nationality and ethnicity of their students, and that the attrition rate for their programs is zero. Furthermore, when surveying members of professional organizations, it is assumed that all members work in positions related to educational measurement, and inversely, non-members do not belong to the field. Regardless of these assumptions, none of the published studies provided direct evidence of the annual supply of educational measurement specialists or whether supply has changed over time.

Therefore, to better understand the supply-side aspect of the perceived educational measurement specialist labor shortage, it is important for us to know how many graduates are produced on an annual basis, whether supply is growing over time, and if there is potential to improve supply by increasing various demographic subgroup representation. Addressing this 
information is the objective of this study, and particular focus is placed on educational measurement doctoral graduates within the United States. To do so, longitudinal data collected between 1997 and 2016 by the National Science Foundation's (NSF) Survey of Earned Doctorates (SED) is utilized. It is argued that the use of this secondary data source is an improvement over previous survey-related data in that: (a) annual graduation rates over time can be obtained; (b) response rates are expected to be high as many institutions require students to complete the SED prior to graduation; (c) responses may be more accurate as they are directly obtained from graduates as opposed to faculty members. The specific research questions addressed in this study are:

1. Has the annual supply of doctoral graduates in educational measurement changed from 1997 to 2016 ? Specifically,

- Is there gender parity in the supply of graduates? Has gender representation changed over the time span examined?

- Has the growth rate of international graduates outpaced that of U.S. doctoral degree recipients?

- Has the racial/ethnic makeup of educational measurement specialists changed over time?

2. What are the post-graduation outcomes for doctoral recipients in educational measurement? Specifically,

- How much debt do students accrue in pursuit of their doctoral degrees?

- What is the percentage of graduates who report obtaining a position upon graduation?

- For those that have a position, in what sector (e.g., academia, industry, government) are they employed and what is their starting salary? 
- Do these post-graduation outcomes vary across race/ethnicity and/or gender? Findings have the potential to better elucidate the supply-side aspect of the proposed labor shortage and provide recommendations for targeted recruitment efforts.

\section{Method}

\section{Data Source}

Data were collected from the National Science Foundation's (NSF) Survey of Earned Doctorates, which is an annual survey administered to approximately 50,000 new research doctorate graduates from U.S. universities to gather knowledge about their educational histories, funding sources, and post-doctoral plans. The SED is considered a census of all individuals receiving a research doctorate from a doctorate-granting academic institution in the United States; and it represents the most comprehensive collection of doctoral graduate data in the U.S. For example, of the 54,904 individuals earning a research doctorate in 2016 from 436 institutions, $91.8 \%$ completed the SED. The NSF constructs a more basic record from nonrespondents to include doctoral institution, year of doctorate, field of doctorate, type of doctorate using data collected from commencement programs, graduation lists, and other public records. The NSF has noted that nonresponse is concentrated primarily in specific institutions. For example, 44 institutions account for $68 \%$ of the total unit nonresponse. Incomplete student responses are accepted/recorded on the SED; and our analyses used all available student responses.

This study examined data collected for doctoral graduates in educational measurement from 1997-2016. Specifically, graduates who selected the following field codes were included in our sample: Psychometrics (630), Quantitative Psychology (633), Psychometrics \& Quantitative Psychology (633), Educational Measurement \& Statistics (814), Educational Statistics and 
Research (815), Educational Statistics/Research Methods (815), Educational Testing, Evaluating, \& Measurement (820), or Educational Assessment, Testing, \& Measurement (820). For each year, NSF reported the number of doctoral recipients by: (a) total; (b) temporary visa holders (hereon referred to as international students); (c) U.S. citizens and permanent residents; (d) race or ethnicity of U.S. citizens and permanent residents (American Indians, Asians, Blacks, Hispanics, Whites, two or more races, other/unknown, and ethnicity not reported); (e) gender; (f) employment type; (g) employment sector; (h) starting salary (data collected beginning in 2007); (i) graduate education debt accrued. Although the SED has been collecting data from doctoral graduates since 1957, we focused our analysis on students earning their doctorate degrees from 1997 to $2016(n=3,124)$. These years were chosen as they provide data for graduates across 20 years and also provide an update from the last comprehensive survey of educational measurement graduate students conducted by Patellis et al. (1997). Still, given the nature of the SED data (collected directly from students to include post-graduate outcomes with a response rate greater than $90 \%$ ), we argue that this study is less subject to the methodological limitations of the Patellis et al. study (e.g., high nonresponse rates, indirect information about students collected from faculty members).

\section{Data Analysis}

Data were analyzed primarily using descriptive statistical methods. In most cases, we provide both the frequency (including percentages) and/or mean values. Per NSF policy, when cell sizes were smaller than 10 , subgroups were combined or not reported to ensure anonymity. To provide a full picture of the supply of measurement professionals over the last two decades, we calculated the compound average growth rate (CAGR) which represents the cumulative effect 
of increases and decreases in the graduation rates of measurement professionals on the initial rate over the twenty-year period:

$$
\left(\frac{\text { Ending value }}{\text { Starting value }}\right)^{\frac{1}{\# \text { of years }}}-1
$$

When investigating post graduate outcomes, mean differences across starting salary were examined using between-subjects analysis of variance. Possible differences in post-graduation employment and debt were investigated using the chi-square test for independence.

\section{Results}

In the United States, 3,124 doctoral degrees were awarded in educational measurement from 1997 to 2016. These degrees were conferred across 242 institutions, with the University of Iowa $(n=120)$, University of California, Los Angeles (UCLA; $n=93)$, Boston College $(n=79)$, Michigan State University $(\mathrm{n}=78)$, and Ohio State University Main Campus $(\mathrm{n}=74)$ awarding the greatest number of doctorates. Although graduates came from a diverse number of universities, the top 10 awarding institutions accounted for $27 \%$ of all degrees. These institutions geographically spanned the United States with representatives from the West, Midwest, MidAtlantic, and Northeast regions.

\section{Has the annual supply of doctoral graduates in educational measurement changed}

\section{from 1997 to $2016 ?$}

Figure 1, provides results on the overall trend of doctoral degrees awarded during this time span. An examination of this figure points to a number of interesting trends. To begin with, across the 20 years examined, the total number of graduates each year exceeded 100 , with the minimum and maximum number of graduates equal to 102 and 199, respectively. However, annual fluctuations were observed in the data. As an example, of the 19 time periods studied, only nine were found to have positive annual growth, while the remaining 10 saw reductions in 
the number of graduates. The largest annual growth $(26 \%)$ was observed between $2005(n=132)$ and $2006(\mathrm{n}=166)$, and the biggest percentage drop-off of graduates $(-13 \%)$ occurred between $2009(n=177)$ and $2010(n=154)$. To account for these fluctuations, the compound annual growth rate was calculated and found to be equal to $2.7 \%$, indicating small, positive annual increases in the number of graduates produced over the 20 years examined.

\section{Has the Growth Rate of International Graduates Outpaced that of U.S. Doctoral Degree Recipients?}

Of the 3,124 doctoral degrees awarded between 1997 and 2016 in the United States, approximately $30 \%$ of graduates self-identified as possessing a nationality outside of the United States $(\mathrm{n}=934)$. A closer examination of these graduates' nationalities indicates that nearly twothirds of all international graduates came from Asia. The top three most represented countries were China $(\mathrm{n}=312)$, South Korea $(\mathrm{n}=152)$, and Taiwan $(\mathrm{n}=90)$. Fewer numbers of graduates indicated Turkish $(\mathrm{n}=38)$, Canadian $(\mathrm{n}=31)$, Indian $(\mathrm{n}=28)$, Japanese $(\mathrm{n}=18)$, or German $(\mathrm{n}=$ 17) citizenship. Over the 20 years examined, the compound average growth rate was $156 \%$ larger for international students (4.3\%) when compared to U.S. citizens who earned doctoral degrees (1.7\%). This result indicates that the growth rate of international students far outpaced that of U.S. citizens earning doctoral degrees in the U.S. over the years examined.

\section{Is There Gender Parity in the Supply of Graduates?}

Figure 2 shows the growth trend in the field by gender. The supply of women (CAGR $=$ $3.4 \%)$ entering the field of measurement has outpaced that of men (CAGR $=1.5 \%)$ consistently since the turn of the century. Indeed, the growth in the field in the last ten years (2007 to 2016) can be attributed primarily to the number of female degree earners with international female students $(\mathrm{CAGR}=4.8 \%)$ outpacing all other subgroups including international male students 
$(\mathrm{CAGR}=3.3 \%)$, domestic female students $(\mathrm{CAGR}=2.4 \%)$, and especially domestic male students

$(\mathrm{CAGR}=0.4 \%)$. During this period, women earned $62 \%$ (1115 out of 1801$)$ of the doctoral degrees awarded.

\section{Has the Racial/Ethnic Makeup of Educational Measurement Specialists Changed Over} Time?

Table 1 provides a demographic breakdown of the sample. Because of the small sample size for Native American, Multi-Race, NA, and Pacific Islander graduates (often resulting in cell sizes smaller than five), this analysis focuses on the supply and post graduate outcomes of students who identify as White, Black, Hispanic, or Asian. Compared to other race/ethnic groups, White and Asian (international \& domestic) students annually earned more degrees, comprising, on average, $85 \%$ of total graduates each year (see Figure 3). Specifically, within these subgroups, most graduates identified as White (57.3\%) or Asian (25.1\%). Of the other race/ethnic groups in the field, Black (6.8\%) and Hispanic (4.4\%) graduates were the largest. An examination of these groups' graduation rates showed that although the compound average growth rate for Black (4.2\%) and Hispanic (3.7\%) doctorate earners was greater than that of their White counterparts $(1.4 \%)$, the gap between these racial/ethnic groups remained large. In fact, the field failed to graduate more than 10 Hispanic and 20 Black students in a single year from 1997 to 2016. In contrast, since 2007, the minimum annual number of Asian and White graduates was $44(\mathrm{CAGR}=4.4 \%)$ and $73(\mathrm{CAGR}=1.4 \%)$ respectively. 


\section{What Are the Post-Graduation Outcomes for Doctoral Recipients in Educational Measurement?}

To examine post-graduate outcomes for doctoral recipients, we looked at post-graduation employment status, debt students accrued financing their doctoral educations, work type, work sector, and beginning salary.

\section{Post-Graduation Status}

Table 2 includes the post-graduation status of students at the time of survey completion disaggregated by race/ethnic groups. Approximately three quarters $(75.8 \%)$ reported that they would be returning to/continuing pre-doctoral employment, had accepted a position, or were actively negotiating an offer. Only $17.7 \%$ reported seeking a position but holding no offers of employment. Chi-square tests of significance revealed a relationship between students' reported race/ethic group and employment status $\left(\chi^{2}=60.29, d f=3, p=.00\right)$. Specifically, larger percentages of White (82.5\%) students reported offers of employment than their Black (69\%) or Asian (70.4\%) counterparts.

\section{Debt}

Most students (59.2\% overall) incurred no debt earning their doctoral grades, while approximately one-fifth $(21.5 \%)$ reported incurring more than $\$ 30 \mathrm{k}$ of debt in pursuit of their doctoral degrees. A similar pattern emerged when the data were disaggregated by gender with most men (58\%) and women (59\%) incurring no debt and approximately one-fifth of men $(21.7 \%)$ and women $(21.3 \%)$ incurring over $\$ 30 \mathrm{k}$ in debt. Dissimilar patterns emerge, however, when examining the debt patterns of doctoral students by race and ethnicity. When asked about the debt they have incurred in pursuit of their doctoral degrees, $46.6 \%$ of White students and $63.1 \%$ of Asian students indicated they incurred no debt. In comparison, only $32.9 \%$ of Black 
students and $40.1 \%$ of Hispanic students made the same claim. Moreover, among students who did report incurring debt (41\% overall), Black and Hispanic students incurred more debt than their White and Asian peers (see supplemental file Figure A for representation). Indeed, over one-third of Black and one-quarter of Hispanic graduates reported graduating with more than $\$ 30,000$ in debt from their doctoral studies alone compared to less than one-fifth $(18 \%)$ of White graduates. Similarly, $8.0 \%$ of Black students reported that they owed more than $\$ 90 \mathrm{~K}$ as a consequence of pursuing their doctoral degrees; whereas fewer than three percent of White students reported such high doctoral student-related debt.

\section{Work Activity/Type}

We examined graduates reported primary work activity post-graduation $(n=2,051)$ over the twenty-year period (see supplemental file Figure B). Among students who indicated that they were returning/continuing predoctoral employment or had signed a contract/made a definite commitment, most intended to work in research and development (52\%), followed by teaching (22\%), management and administration (15\%), and professional services to others (9\%); and this trend was consistent over the entire 20 -year period. We also examined an aggregate of the data over the twenty-year period with respect to percentages across gender and all four racial/ethnic groups (see supplemental Figure $\mathrm{C}$ for representation). Overall patterns remain similar across three racial/ethnic groups (White, Hispanic, Asian) with the greatest percentage of graduates entering research and development followed by teaching. For White and Asian graduates these percentages are nearly identical across sex; but we see that a larger percentage of Hispanic men (64\%) are employed in "Research and Development" than Hispanic women (51\%). However, we see a different pattern for Black graduates overall in which the largest percentage entered 
"Management or Administration" and far fewer entered "Research and Development." Interestingly, $38 \%$ of Black men entered "Teaching"-more than any other subgroup.

\section{Work Sector}

In addition to examining work activity, we also sought to look at trends with respect to the type of employers (i.e., employment sector) graduates would work for post-graduation. For those who reported the sector of their future employment $(n=2,130)$ from 1997-2016, most planned to enter the academy (52\%), followed by those planning to enter industry (30\%). Fewer students indicated they would begin working for other educational institutions $(10 \%)$ or the government (9\%). In Figure 4 we see that the number of graduates working for "other educational institutions" (e.g., school districts) and the government has remained relatively unchanged in the last 20 years; and we also see a small increase in the number of graduates working in universities/colleges or industry.

In addition, we examined these work sector data by gender and racial/ethnic groups (see supplemental file Figure D for representation). Here, we do see some interesting patterns: across all race/ethnic groups, the largest percentage of graduates entered the academy (White, 50.8\%, Hispanic, $60.7 \%$, Asian, $51.3 \%$, \& Black 48.6\%). However, when disaggregating these data by gender, we see that a far greater percentage of Black (63.6\%) and Hispanic (71.8\%) male graduates enter the academy than Black (38.6\%) and Hispanic (5.1\%) females. Asian graduatesboth male and female-were much less likely than other graduates to enter the government or other educational institution sector with a large percentage (41.2\%) instead opting to enter industry. Moreover, a larger percentage of Black students (22.5\%) reported their intention to work (or that they are currently working) in other educational institutions. 
When examining doctoral education debt accrual within and across work sectors, some interesting patterns emerged (see supplemental file Figure E). The majority of students within all sectors reported that they accrued no debt pursuing their doctoral education. Still, a smaller percentage of graduates made this claim who intended to enter the government and other educational institutions (51\%) than those who reported their intentions to enter the academy or industry (64\%). Both the government (30\%) and other educational institution (28\%) sectors included the largest percentage of students with doctoral education debt greater than $\$ 30 \mathrm{k}$; whereas far smaller percentages of students entering the academy (18\%) or industry (15\%) reported such high levels of doctoral education debt.

\section{Salary}

To get a more complete sense of students' financial post graduation outcomes, in addition to the debt they accrued earning their doctoral degrees, we also examined students' reported beginning salaries. The average beginning salary (for students who reported this information) was $\$ 70,440(S D=\$ 25,724)$ from $2007-2016$. Given the relatively long time period of ten years, we also calculated the average salary for the most recent five-year period (2012-2016) and found it to be nearly identical $(\$ 70,621, S D=\$ 24,709)$, suggesting that starting salaries have remained static over time. When disaggregated by race/ethnicity, we found negligible differences that were not statistically significant in the average starting salaries of White $(\$ 71,684, S D=\$ 27,223)$, Black $(\$ 72,047, S D=\$ 72,047)$, Hispanic $(\$ 66,439, S D=\$ 21,927)$, and Asian $(\$ 66,589, S D=$ $\$ 21.269)$ graduates from $2007-2016\left(\mathrm{~F}_{(3,601)}=1.526, p=.21\right)$. Furthermore, we found similar results when disaggregating average beginning salary by gender. Specifically, no statistically significant differences were found in the average starting salaries of men $(\$ 72,387, S D=$ $\$ 29,182)$ and women $(\$ 69,029, S D=\$ 22,833)$ from 2007-2016 $\left(t_{478}=1.55, p=.12\right)$. 
We also examined the average starting salaries of graduates by sector of employment aggregated over the ten-year period. Students entering industry $(\$ 84,918, S D=\$ 24,803)$ postgraduation reported considerably higher starting salaries for both men $(\$ 91,489, S D=\$ 26,981)$ and women $(\$ 80,741, S D=\$ 22,447)$ than students entering the academy $(\$ 59,484, S D=$ \$20,807). Students entering into the other educational institution sector (e.g., school districts) also reported much higher starting salaries $(\$ 81,428, S D=\$ 26,145)$ for both men $(\$ 85,500, S D=$ $\$ 32,399)$ and women $(\$ 78,819, S D=\$ 21,269)$ than male $(\$ 59,303, S D=\$ 22,399)$ and female $(\$ 59,623, S D=\$ 19,553)$ graduates entering the academy. Moreover, students entering the government sector $(\$ 69,970, S D=\$ 23,985)$ reported salaries lower than those entering industry or other educational institutions with female graduates $(\$ 66,063, S D=\$ 18,113)$ entering government sector earning approximately $\$ 8,000$ less than their male $(\$ 74,190, S D=\$ 28,832)$ counterparts. Still, doctoral graduates from measurement programs between 2012-2016, on average, reported higher beginning salaries than graduates from other closely related fields such as General Psychology $(\$ 56,734, S D=\$ 31,042)$ or Educational Psychology $(\$ 56,672, S D=$ $\$ 23,221)$.

\section{Discussion}

In this study, we sought to address a critical concern in the field of educational measurement, which is the need to understand whether there has been a stable and ongoing production of measurement professionals over time. Our findings revealed several key points. First, from 1997-2016, a steady, positive supply of measurement professionals was observed. This observation was largely bolstered by a rapidly increasing number of international students earning doctoral degrees in measurement. In fact, the number of international graduates far outpaced domestic degree earners. Congruent with Brennan and Plake's description of 
enrolled/current doctoral students in 1990 as well as Patellis et al.'s findings in 1997, approximately $30 \%$ of all doctoral degree earners over the last 20 years have been international students. Second, the growth rate of women in the field outpaced that of men. Third, racial/ethnic diversity in the field has remained largely absent. Whites and Asians comprised, on average, $85 \%$ of the total graduates. These results echo/mirror those of Packman et al. (2010)'s survey of measurement professionals with over $90 \%$ of respondents identifying as White or Asian. In contrast, the number of Black and Hispanic professionals remained disproportionately small. A fourth key finding was that Black graduates accrued higher levels of debt than their White, Hispanic, and Asian counterparts in financing their doctoral education. Finally, although the largest percentage of graduates entered the academy upon graduation, the average starting salaries for graduates entering industry was $43 \%$ higher than those entering the academy; and this pattern holds for those entering government (18\% higher), and other educational institutions ( $37 \%$ more). In this discussion, we place these highlighted findings into broader social context and discuss the implications for future research.

\section{Racial/Ethnic Parity}

Our findings of race/ethnicity parity echo the results of previous, smaller scale studies in the field (see Patellis, Kolen, \& Parshall, 1997; Packman, Camara, \& Huff, 2010). Specifically, students who identified as Black (6.8\%) or Hispanic (4.4\%) represented fewer than $12 \%$ of all measurement doctoral degree earners, yet, the 2018 U.S. Census estimates that Black (13.4\%) and Hispanic (18.3\%) individuals compose nearly a third of the population (census.gov). According to the National Science Foundation (2017), Blacks, Hispanics, and Native Americans comprised only $13 \%$ of the STEM workforce. As Wilson et al. (2018) wrote with respect to the STEM field, it 
"represents a significant component of the U.S. economy for which there are major commitments of national resources in training at the graduate and professional levels. Questions regarding equity and access to heavily subsidized training resources and opportunities arise as certain populations remain underrepresented in these training pipelines" (p.2)

Moreover, the negative consequences of limited diversity have been well established - especially within STEM disciplines. Poodry (2003) writes that "these consequences include a lack of input in the decisions that are made as to the foci of our scientific efforts, especially in areas that disproportionately impact the populations that are underrepresented and often underserved."

As part of the STEM pipeline, measurement programs should be working not only to increase the number of qualified STEM professionals in the workforce, but also to improve the racial/ethnic diversity of the field. Although the number of doctoral degrees awarded in measurement has steadily increased overall since 1997, this supply is largely bolstered by White and Asian students (i.e., they comprised nearly $83 \%$ of all doctoral degree earners from 19972016). Indeed, the aggregate number of Black and Hispanic graduates remains dismally low. One might argue that the percentage of doctoral graduates in the field of measurement simply reflects the number of BA earning students overall; however, in 2016, 13.7\% of students enrolled in degree granting postsecondary institutions were Black, while only $5 \%$ of students earning a doctorate degree in educational measurement identified as Black. This pattern is similar with Hispanic students as they represent $18.2 \%$ of students enrolled in postsecondary institutions. Moreover, the dismally low numbers of graduates who identify as Native American, Multi-race, or Pacific Islander have been so small over the last twenty years that we are unable to disaggregate data for these groups. 
These findings are particularly troubling given the population that measurement specialists currently serve. This student population is quickly changing not only from an ethnic perspective (White students in K-12 will become a minority by 2024; Kena et al., 2015), but also in terms of linguistic diversity (ELLs; NCES, 2017). Taking this diversity into consideration when developing educational assessments is important as cultural and social norms impact the assessment process by influencing how learning will be assessed, and how responses are evaluated, interpreted, and used (Ercikan \& Solano-Flores, 2016; Harris \& Brown, 2016; Hattie, 2016). Therefore, having more diverse educational measurement specialists at the decisionmaking table may assist the field to more effectively take into consideration the cultural and linguistic diversity of the students being assessed, which may potentially provide more accurate evaluations of the skills, knowledge, and/or abilities measured. These findings certainly point to the need for a more systematic and consistent approach to recruiting measurement professionals from underrepresented groups such as those proposed by Sireci and Khaliq (2002).

\section{Gender Parity}

Although these data suggest a need for widespread and comprehensive recruitment efforts to increase racial/ethnic diversity representation in the field, there is evidence that female representation is considerable and growing. Previous research has provided extensive evidence that women are underrepresented in STEM disciplines despite years of interventions designed to improve gender parity (NSF, 2017). In fact, on average fewer than a third of the world's researchers are women (Wood, 2020). Our findings suggest, however, that the field of educational measurement has made great strides in the recruitment of women to the field. In the last twenty years, over $60 \%$ of measurement graduates have been women with a compound annual growth rate of $3.4 \%$ (compared to only $1.5 \%$ for men). 


\section{Post-Graduation Outcomes}

In addition to examining the characteristics of the supply of measurement professionals, we also examined postdoctoral outcomes for students earning doctoral degrees in measurement. The post-graduate employment rate for $\mathrm{PhDs}$ is quite high ranging from $85-95 \%$ depending on country and area of study (Auriol et al. 2013). With the increasing numbers of individuals earning doctoral degrees, academic positions are no longer the only employment outcome for these graduates (Mowbray \& Halse, 2010). In fact, there has been a decline in the percentage of doctoral graduates who obtain academic positions in the United States (Council of Graduate Schools, 2007) and abroad (Paul \& Perett, 1999; Neuman et al. 2008). We found, however, that large percentages (ranging from 49-61\% across race groups) of students continue to enter the academy, in some capacity, following graduation. Nevertheless, the numbers of students entering industry has also continued to increase during this twenty-year period suggesting that students earning degrees in measurement are taking advantage of these additional post-graduation employment options.

In addition to employment outcomes, we are compelled to highlight the differential financial outlook for students after graduation. Although students of color reported similar starting salaries overall to their White counterparts, we found that Black students accrued far more debt than White and Asian students. This may be explained in part by the fact that a much smaller percentage of Black students received tuition remission while working on their doctoral degrees (54.7\%) compared to White (69.2\%), Hispanic (66.1\%), and Asian (85.4\%) students. This disproportionate finding has direct implications for recruitment and retention in the field as a lack of sufficient funding has been identified as a cause of both lower matriculation and higher attrition rates (see Gardner \& Holley, 2011 and others). Interestingly, although we found that a 
larger percentage of Black graduates entered higher paying sectors, such as educational institutions (22.5\%) and government (10.9\%), than their White, Asian and Hispanic counterparts, a smaller percentage entered industry $(18.1 \%)$ - the sector with the highest average starting salaries. Still, the need to pay off education debt could be an influential factor in these decisions.

\section{Implications for Future Research}

The data available via the SED provides the most accurate evaluation of the supply of educational measurement specialists in the United States to date; however, it is limited in a number of ways. First, individuals graduating in the subfields examined may not go into a job related to educational measurement. Second, not all U.S. degree earners may enter the U.S. workforce, as a large percentage of international graduates and some domestic degree earners may work abroad. Third, this study focuses on the supply of educational measurement professionals from U.S. institutions of higher education. Although there is no prior literature outlining the influence/impact of measurement professionals trained outside of the U.S. entering the U.S. workforce, it is certainly conceivable that universities, companies, and governments have hired - and will continue to hire - measurement professionals trained abroad. Finally, the Survey of Earned Doctorates focuses on earned doctorate degrees and does not take into consideration the supply of measurement professionals who have earned master's degrees alone.

Taken these limitations in mind, the numbers presented in this study may be viewed as an estimate of supply. Future research should focus on interviewing/surveying major testing/measurement companies and measurement programs to determine the extent to which the U.S. workforce includes both professionals trained outside of the U.S. and/or who hold a master's degree only. In addition, an important area of future research is to annually follow graduates to better understand how many of these individuals go into professions in educational 
measurement, the types of positions they are taking, as well as their salary and demographic information (akin to the work done by Packman et al., 2010).

An area of future research not addressed in this study is to better understand the demand for educational measurement specialists in the United States. To date, researchers have simply surveyed members of NCME that were faculty members or employers of educational measurement specialists to ascertain whether there would be expected job growth in academia and industry (Brennan \& Plake, 1990; Patellis et al., 1997). Such an approach may be limited in that responses from survey participants may not generalize to the overall U.S. job market. Furthermore, the findings may be too outdated to determine whether the supply-side results presented in this study are meeting the current demand. As a consequence, our understanding of the educational measurement labor shortage is largely anecdotal. To resolve this issue, one approach would be to webscrape job advertisements for positions in educational measurement posted via online job aggregation websites over a prolonged time period (akin to the work conducted by Rios et al., 2020). Once relevant job advertisements were collected, content analyses would be conducted to ascertain information on the number of new jobs created, the required degree level (master's, doctoral), geographic location, salary information, the job setting (i.e., academia, government, testing industry), etc. Such a study would provide a clearer understanding on whether the supply side of educational measurement specialists is meeting demand.

In addition to examining the experiences of measurement students in doctoral programs, it is important to gain an understanding of how measurement students become aware of the profession. Such information could help inform recruitment efforts, in general, and of ethnic minorities specifically. Though, the little that is known about graduate program recruitment in 
educational measurement suggests that as many as $99 \%$ of educational measurement programs do not actively recruit students in general, let alone diverse students (Patellis et al., 1997). Further study on recruitment is needed to provide best practice guidelines for graduate programs in the field.

Finally, future research should also investigate the experiences of Black and Hispanic students once enrolled in educational measurement doctoral programs, with particular focus on faculty support/mentoring as this has been found to be an important factor for students at all post-graduate levels (Barnes \& Austin, 2009; Bhat et al., 2012; Gonzalez, 2006; Rogers, 2006; Henfield et al., 2011), especially women and underrepresented minorities (see Wilson et al., 2018). The literature suggests, however, that for historically marginalized doctoral students these necessary faculty-student bonds/relationships are far more likely to be formed with faculty from similar minoritized identities. McBay (1986) surveyed Black graduates about their experiences on campus and found that only $40 \%$ reported having good relationships with faculty and that all of those relationships were with Black faculty. In fact, students in that same survey reported that their interactions with White faculty were indeed negative, including racists remarks and biased classroom behaviors. The relatively small numbers of Black and Hispanic graduates in the last 20 years suggests a dearth of measurement faculty from minoritized groups. Consequently, it may prove difficult for minoritized students to establish the necessary faculty support systems to be successful, which may result in higher levels of attrition. Future research on this topic is needed to assist in explaining whether attrition is associated with the low numbers of Black and Hispanic professionals entering the field. 


\section{Conclusion}

For nearly three decades, researchers have been concerned that the educational measurement field is not producing enough graduate-level specialists to meet the growing demand that is driven by the increased use of accountability, formative, credentialing, and admissions assessments in the United States. This study is one of the first to examine the supplyside aspect of the proposed labor shortage by relying on historical data collected by the U.S. federal government. Overall, the annual supply of doctoral-level graduates in the field has doubled over the last 20 years. However, further study is needed to understand whether the current supply is meeting the demand for educational measurement specialists in the U.S. labor market. It is our hope that this paper provides a basis for the field to continue discussions on the perceived labor shortage as well as increasing representation of various underrepresented groups in the field. 


\section{References}

Auriol, L., Misu M., \& Freeman R. A. (2013). Careers of doctorate holders: analysis of labour market and mobility indicators (OECD Science, Technology, and Industry Working Papers, 2013/04). OECD Publishing. https://doi.org/10.1787/5k43nxgs289w-en.

Barnes, B. J. \& Austin, A. E. (2009). The role of doctoral advisors: A look at advising from the advisor's perspective. Innovative Higher Education, 33, 297-315.

Bhat, C. S., Pillay, Y., \& Hudson, D. N. (2012). Supporting African American females in doctoral counseling programs at predominantly White institutions. http://www.counseling.org/resources/library/vistas/2012_vol_1_67-104/2_2012ACAPDFs/Article_92.pdf

Brennan, R. L. (2004). Revolutions and evolutions in current educational testing (CASMA Research Report \#6). University of Iowa.

Brennan, R. L., \& Plake, B. S. (1990). Surveys of programs and employment in educational measurement. Educational Measurement: Issues and Practice, 10(2), 32.

Council of Graduate Schools (2007). Data sources: Trends in new Ph.D.s entering academe, 1970 to 2005 (CGS Communicator Newsletter 40, no. 2).

Ercikan, K., \& Solano-Flores, G. (2016). Assessment and sociocultural context: A bidirectional relationship. In G. T. L. Brown and L. Harris (ed), Handbook of human and social conditions in assessment (pp. 490-505). Routledge.

Finney, S. J., \& Pastor, D. A. (2012). Attracting students to the field of measurement. Educational Measurement: Issues and Practice, 31(2), 2-7. 
Gardner, S. K., \& Holley, K. A. (2011). "Those invisible barriers are real": The progression of first-generation students through doctoral education. Equity \& Excellence in Education, $44,77-92$.

Gonzalez, J. C. (2006). Academic socialization experiences of Latina doctoral students: A qualitative understanding of support systems that aid and challenges that hinder the process. Journal of Hispanic Higher Education, 5, 347-365.

https://doi.org/10.1177/1538192706291141Harris, L. R., \& Brown, G. T. L. (2016). The human and social experience of assessment: Valuing the person and context. In L. R. Harris and G. T. L. Brown (Eds.), Handbook of human and social conditions in assessment (pp. 1 30). Routledge.

Hattie, J. (2016). Forward. In L. R. Harris and G. T. L. Brown (Eds.), Handbook of human and social conditions in assessment (pp. ix - xii). Routledge.

Henfield, M. S., Owen, D., \& Witherspoon, S. (2011). African American students in counselor education programs: Perceptions of their experiences. Counselor Education \& Supervision, 50, 226-242.

Kena, G., Hussar, W., McFarland, J., de Brey, C., Musu-Gillette, L., Wang, X., Zhang, J., Rathbun, A., Wilkinson-Flicker, S., Diliberti, M., Barmer, A., Mann, F., Velez, E., Nachazel, T., Smith, W., \& Ossolinski, M. (2016). The condition of education 2016 (NCES 2016-144). U.S. Department of Education, National Center for Education Statistics. Washington, DC. Retrieved April 28, 2020 from http://nces.ed.gov/pubsearch.

McBay, S. (1986). The Racial Climate on the MIT Campus. A Report of the Minority Student Issues Group. MIT Office of the Dean for Student Affairs 
Mowbray, S., \& Halse, C. (2010). The purpose of the PhD: Theorising the skills acquired by students. Higher Education Research \& Development, 29, 653-664.

Neumann, R., Kiley, M. \& Mullins G. (2008). Australian doctoral graduates: where are they going. In M. Kiley and G. Mullins (Eds.), Quality in postgraduate research: Research education in the new global environment (pp. 84-89). The Center for Educational Development and Academic Methods, The Australian National University. Conference Proceedings of the 2008 Quality in postgraduate research conference, April 17-18, in Adelaide, South Australia.

NSF (2017). 2015 doctorate recipients from U.S. universities. National Science Foundation.

Packman, S., Camara, W. J., \& Huff, K. (2010). A snapshot of industry and academic professional activities, compensation, and engagement in educational measurement. Educational Measurement: Issues and Practice, 29(3), 15-24.

Patellis, T., Kolen, M. J., \& Parshall, C. (1997). Surveys of programs and employment in educational measurement. Educational Measurement: Issues and Practice, 16(3), 25-27.

Paul, J., \& Perret, C. (1999). PhD graduates in France: training, careers and policy issues. In O. Kivinen, S. Ahola, \& P. Kaipainen (Eds.), Towards the European model of postgraduate training (pp. 157-186). Research Unit for the Sociology of Education.

Poodry, C. A. (2003). Minorities in the chemical workforce: Diversity models that work (A workshop report to the Chemical Sciences Roundtable). National Academies Press.

Rios, J. A., Ling, G., Pugh, R., Becker, D., \& Bacall, A. (2020). Identifying critical 21st-century skills for workplace success: A content analysis of job advertisements. Educational Researcher, 49(2), 80-89. 
Rios, J. A., Randall, J., \& Donnelly, M. (2019). An analysis of college choice information provided on graduate program websites: Implications for improving applicant diversity in educational measurement. Educational Measurement: Issues and Practice, 38(4), 67-77.

Rogers, A. M. (2006). Factors leading to successful attainment of doctoral degrees in education by African American women (Doctoral dissertation). ProQuest

Dissertations and Theses database. (UMI No.3257274)

Sireci, S. G. (2000). Recruiting the next generation of measurement professionals. Educational Measurement: Issues and Practice, 19(4), 5-9.

Sireci, S. G., \& Khaliq, S. N. (2002). NCME members' suggestions for recruiting new measurement professionals. Educational Measurement: Issues and Practice, 21(3), 19-24.

Wilson, M.A., DePass, A.L., Bean, A.J. (2018). Institutional interventions that remove barriers to recruit and retain diverse biomedical Ph.D. students. CBE-Life Sciences Education, 17(2), $1-14$.

Wood, J. (2020). 3 things to know about women in STEM. World Economic Forum. https://weforum.org/agenda/2020/02/stem-gender-inequality-researchers-bias/ https://www.nsf.gov/statistics/2018/nsf18304/survey-description.cfm 
Table 1

Demographic table by average age, race, and sex

\begin{tabular}{|c|c|c|c|c|c|}
\hline $\begin{array}{l}\text { Race/Ethnic } \\
\text { Group }\end{array}$ & & $\begin{array}{c}\text { Average } \\
\text { Age }\end{array}$ & Male & Female & Total \\
\hline \multirow[t]{3}{*}{ White } & & 37.5 & 799 & 992 & 1791 \\
\hline & U.S. & 37.9 & 717 & 928 & 1645 \\
\hline & Non-U.S. & 33.1 & 82 & 62 & 144 \\
\hline \multirow[t]{3}{*}{ Black } & & 38.0 & 82 & 131 & 213 \\
\hline & U.S. & 38.2 & 57 & 112 & 169 \\
\hline & Non-U.S. & 32.5 & 25 & 18 & 43 \\
\hline \multirow[t]{3}{*}{ Hispanic } & & 39.5 & 64 & 73 & 137 \\
\hline & U.S. & 39.1 & 46 & 56 & 102 \\
\hline & Non-U.S. & 40.2 & 18 & 17 & 35 \\
\hline \multirow[t]{3}{*}{ Asian } & & 34.1 & 258 & 527 & 786 \\
\hline & U.S. & 36.7 & 33 & 67 & 100 \\
\hline & Non-U.S. & 33.7 & 225 & 459 & 684 \\
\hline \multirow[t]{3}{*}{ Multi-Race } & & 36.8 & 22 & 21 & 43 \\
\hline & U.S. & 37.2 & 19 & 21 & 40 \\
\hline & Non-U.S. & 31.8 & 3 & - & 3 \\
\hline \multirow[t]{3}{*}{$\mathrm{NA}^{\mathrm{a}}$} & & 33.5 & 60 & 73 & 134 \\
\hline & U.S. & 33.5 & 14 & 11 & 25 \\
\hline & Non-U.S. & - & 12 & 10 & 22 \\
\hline \multirow[t]{3}{*}{ Grand Total $^{\mathrm{b}}$} & & 36.6 & 1290 & 1832 & 3124 \\
\hline & U.S. & 37.4 & 924 & 1264 & 2190 \\
\hline & Non-U.S. & 34.0 & 366 & 568 & 934 \\
\hline
\end{tabular}

${ }^{a}$ NA: Not Applicable: includes respondents for whom race was not included in the survey (i.e., “other") and respondents who opted not to provide race and/or ethnicity information

${ }^{\text {b}}$ Grand total includes data from race/ethnic groups with cell values too small to include in table.

Note. Two recipients without their sex information were included. 
Table 2

Post-Graduation Employment Status by Race

\begin{tabular}{lccc}
\hline Race/Ethnicity & $\begin{array}{c}\text { Postdoc/degree program } \\
\text { or other work }\end{array}$ & No offer of employment & Total \\
\hline \multirow{2}{*}{ White } & 1478 & 254 & 1,791 \\
\multirow{2}{*}{ Black } & $(82.5 \%)$ & $(14.2 \%)$ & $(100 \%)$ \\
\multirow{2}{*}{ Hispanic } & 147 & 59 & 213 \\
& $(69.0 \%)$ & $(27.7 \%)$ & $(100 \%)$ \\
Asian & 106 & 23 & 137 \\
\multirow{2}{*}{ Total } & $(77.4 \%)$ & $(16.8 \%)$ & $(100 \%)$ \\
& 553 & 198 & 786 \\
& $(70.4 \%)$ & $(25.2 \%)$ & $(100 \%)$ \\
& 2367 & 553 & 3124 \\
& $(75.8 \%)$ & $(17.7 \%)$ & $(100 \%)$ \\
\hline
\end{tabular}

Note: 'Postdoc or other work' is created by combining four categories: 'Returning to, or continuing in, predoctoral employment', 'Accepted or began a postdoc or other work', 'Negotiating an offer of employment with one or more specific organizations', and 'Enrolled in a full-time degree program'. 'Do not plan to work or study' and 'Other' response options are not considered here because of their small sample sizes. 


\section{Figure 1}

Doctoral Degrees Earned in Educational Measurement/Psychometrics, U.S. \& Non-U.S. Students

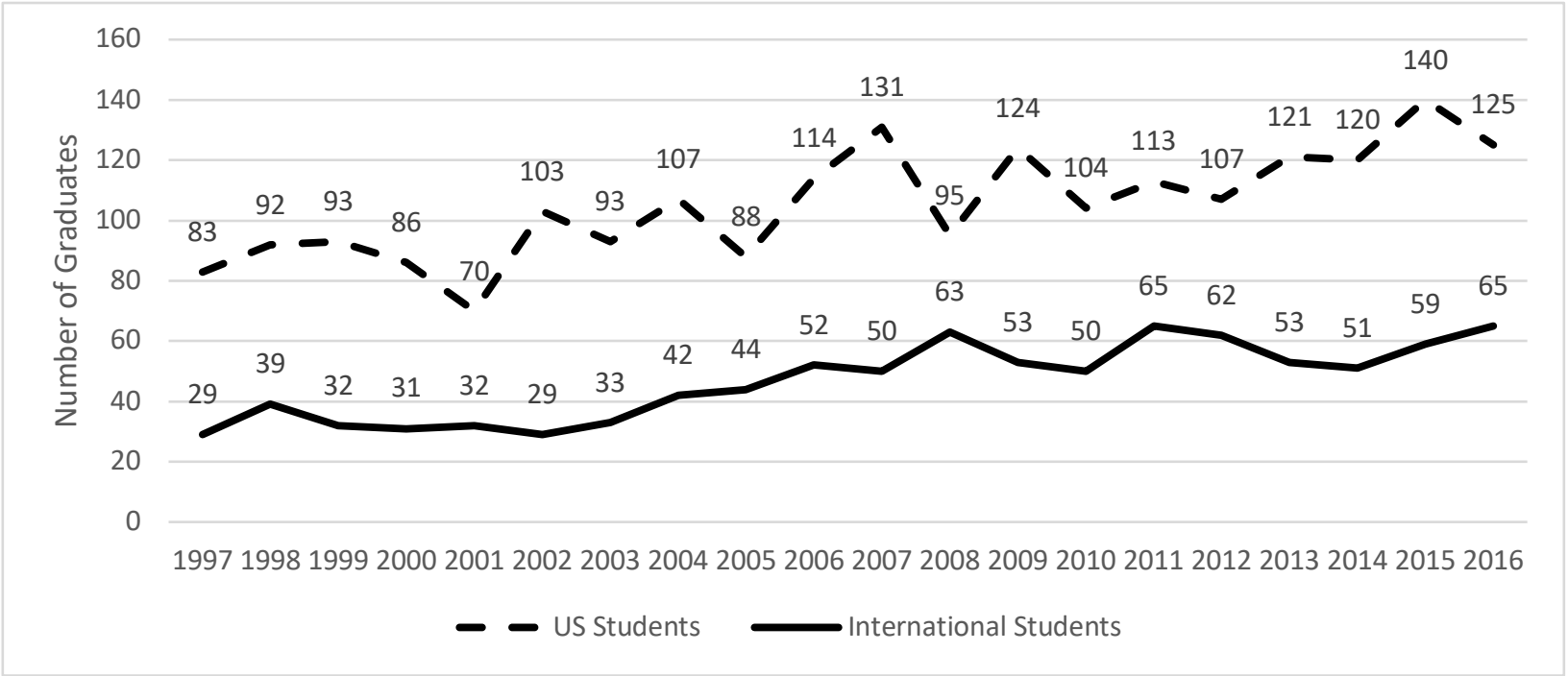

Figure 2

Doctoral Degrees Earned by Gender

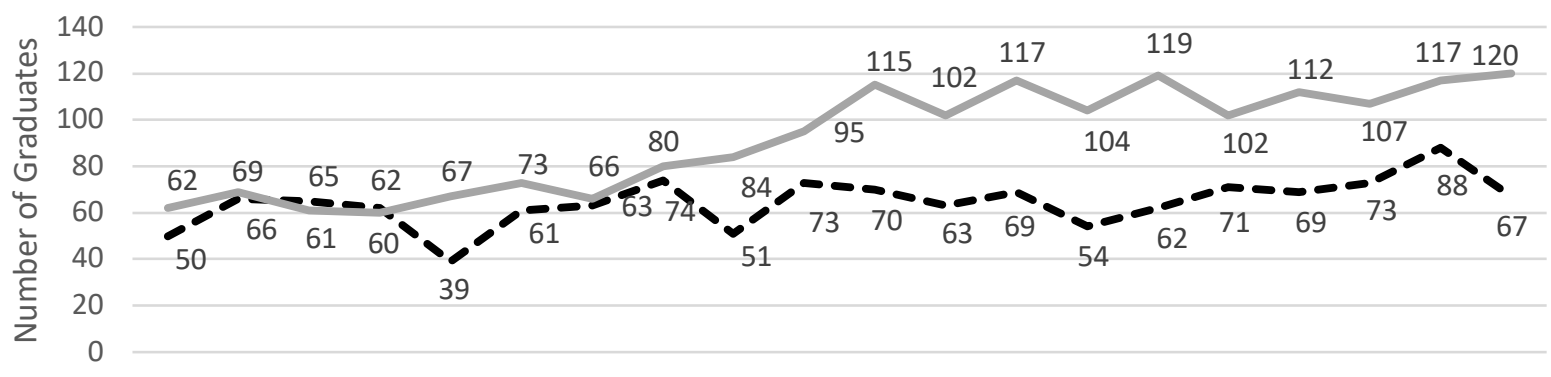

19971998199920002001200220032004200520062007200820092010201120122013201420152016

- Male Female 


\section{Figure 3}

\section{Doctoral Degrees Earned by Race}

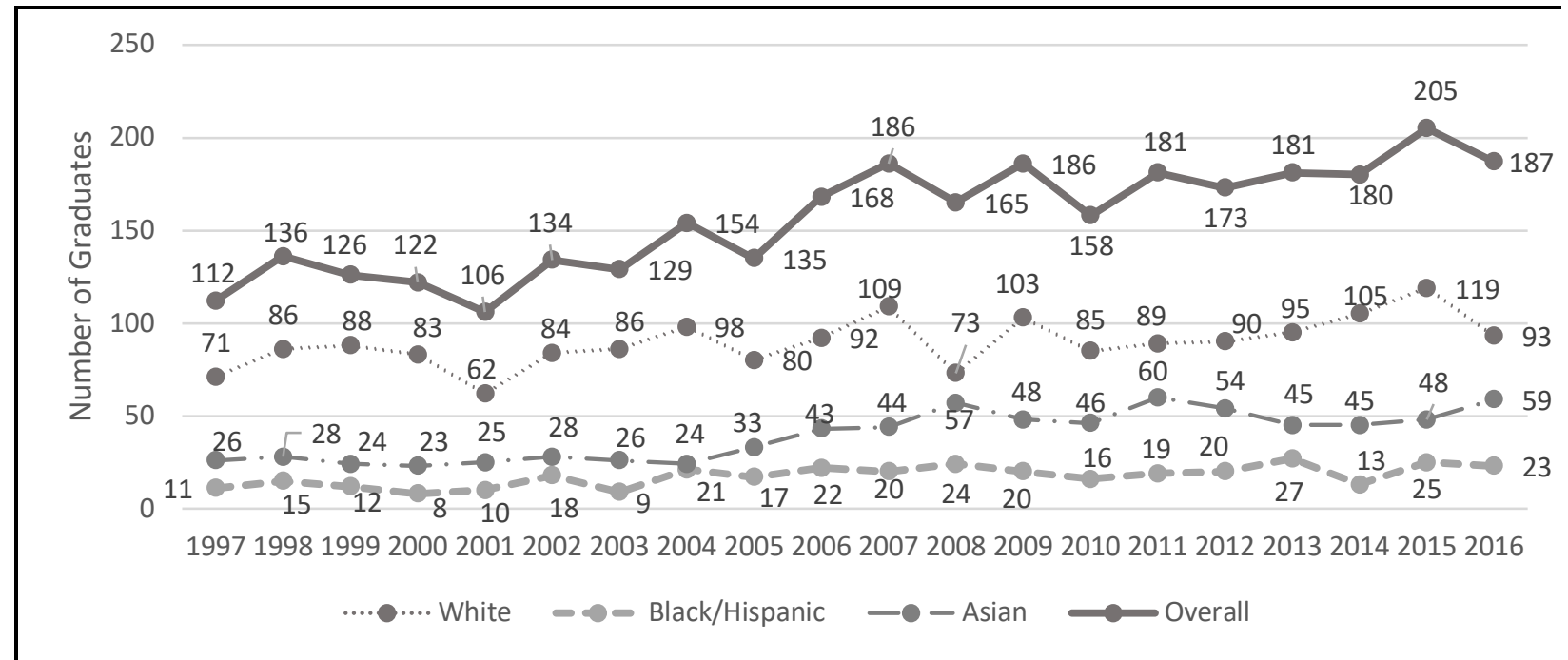

\section{Figure 4}

\section{Post-Graduation Type/Sector of Employer for Students with Secured Employment}

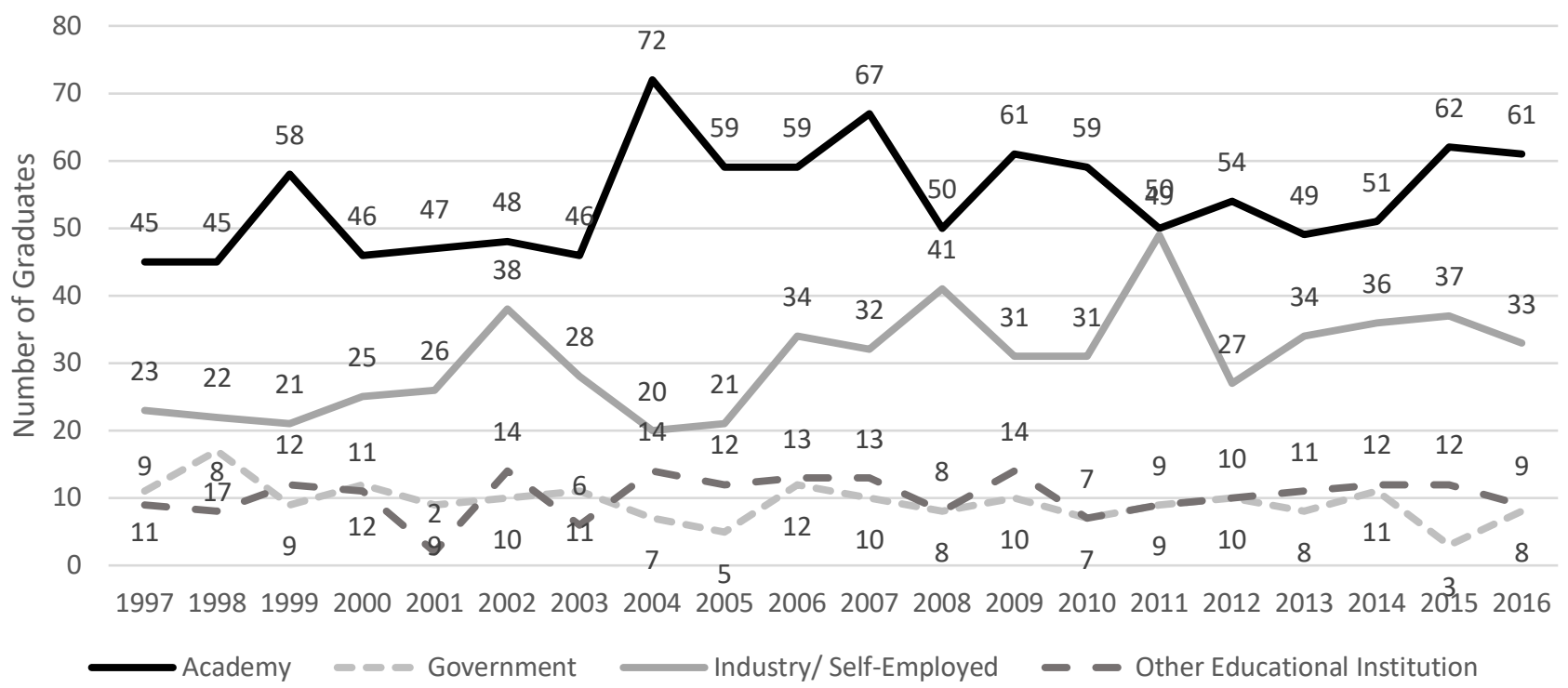

